\title{
Moisture distribution in wall-to-floor thermal bridges under the analysis of coupled heat and moisture transfer
}

\author{
Yucong Xue ${ }^{a *}$, Yifan Fan ${ }^{\mathrm{a}}$, Jian Ge \\ a College of Civil Engineering and Architecture, Zhejiang University, Hangzhou, China
}

\begin{abstract}
A little change of moisture content in thermal bridges (TBs) can lead to a big difference in heat and moisture transfer here as heat transfers more violently at TBs than the main part of walls. We aimed to (1) reveal the moisture distribution in the typical TB (i.e., wall-to-floor thermal bridge, WFTB) and its surrounding area, and (2) find high-risk areas for condensation. The transient numerical simulations lasted for two years were performed to model the moisture distribution. Simulated results show that the moisture distribution presents significant seasonal and spatial difference due to the WFTB, and the interface between WFTBs and the main part of walls has likelihood of condensation in winter.
\end{abstract}

Peer-review under the responsibility of the organizing committee of the ICMB21.

Keywords: wall-to-floor thermal bridge, heat and moisture transfer, transient numerical simulation, condensation

\author{
Nomenclature \\ HSCW hot summer and cold winter \\ HAMT coupled heat and moisture transfer \\ TB thermal bridge \\ WFTB wall-to-floor thermal bridge
}

\section{Introduction/Background}

The moisture content in envelopes impacts energy dissipation and water condensation by modifying both heat and moisture transfer characteristics in building envelopes. Such influence becomes more obvious when envelopes exposed to a hot-humid climate, such as the hot summer and cold winter (HSCW) climate zone in China. The previous study has demonstrated that the cooling, heating and yearly load are significantly underestimated when the moisture transfer is neglected, revealing the importance of the analysis of coupled heat and moisture transfer (HAMT) ${ }^{[1]}$. However, the process of moisture transfer on thermal bridges (TBs) has not been paid enough attention, resulting in an incomprehensive understanding of the moisture distribution in envelopes. TBs have more severe heat transfer compared with the other parts. A little change of moisture content in TBs can, therefore, lead to a big difference in the heat transfer, as the thermal properties have a marked correlation with the moisture content.

Frame structures have been utilized widely in both existing buildings and new buildings, in which the beam, column, and floor bear all of the weight. Reinforced concrete is usually adopted to cast such structures due to its satisfactory mechanical property. However, the high thermal conductivity of reinforced concrete makes the frame structure $\mathrm{TBs}^{[2,3]}$. The wall-to-floor thermal bridge (WFTB) occupies the largest area with the most massive heat flux. Therefore, the WFTB is employed as the object in our study to (1) reveal the moisture distribution, and (2) find high-risk areas for condensation. According to the existing atlas about the construction methods for the self-insulation wall, the vapour barriers are not adopted in our model. Moreover, the structure is considered to be perfectly airtight to eliminate the influence of airflow on HAMT.

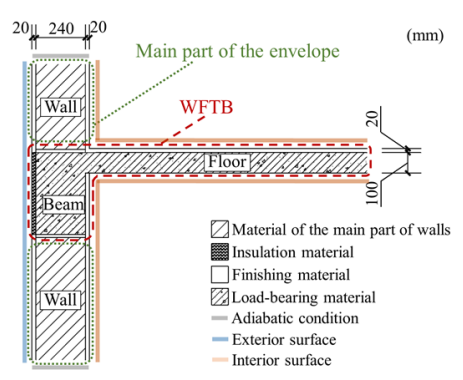

Figure 1 . The geometry of a typical WFTB and the boundary conditions.

Table 1. Hygrothermal properties of materials used in the WFTB.

\begin{tabular}{|c|c|c|c|c|}
\hline & Wall & Finishing & Insulation & Load-bearing \\
\hline$K\left(\mathrm{~W} \cdot \mathrm{m}^{-1} \cdot{ }^{\circ} \mathrm{C}^{-1}\right)$ & $0.64 \ln \left(\omega_{\mathrm{m}}+1\right)^{1.06}+0.19$ & $0.36 \ln \left(\omega_{\mathrm{m}}+1\right)^{0.22}+0.56$ & $0.01 \ln \left(\omega_{\mathrm{m}}+1\right)^{0.35}+0.03$ & 1.74 \\
\hline$\rho\left(\mathrm{kg} \cdot \mathrm{m}^{-3}\right)$ & 643.80 & 1452.11 & 22.06 & 2070.11 \\
\hline$C_{\mathrm{p}}\left(\mathrm{J} \cdot \mathrm{kg}^{-1} \cdot{ }^{\circ} \mathrm{C}^{-1}\right)$ & $920+4186 \omega_{\mathrm{m}}$ & $840+4186 \omega_{\mathrm{m}}$ & $1380+4186 \omega_{\mathrm{m}}$ & $970+4186 \omega_{\mathrm{m}}$ \\
\hline \multirow[t]{2}{*}{$D_{\mathrm{w}}\left(\mathrm{m}^{2} \cdot \mathrm{s}^{-1}\right)$} & $6 \mathrm{E}-10$ & $\exp \left[\sum_{i=0}^{3} a_{i} \cdot\left(\omega_{\mathrm{m}} \cdot \rho / 1000\right)^{i}\right]$ & $1 \mathrm{E}-20$ & $\exp \left[\sum_{i=0}^{5} a_{i} \cdot\left(\omega_{\mathrm{m}} \cdot \rho-37\right)^{i}\right]$ \\
\hline & \multicolumn{2}{|c|}{$a_{0-3}=-40.4,83.3,-176.0,123.9$} & \multicolumn{2}{|c|}{$a_{0-5}=-39.3,7.0 \mathrm{E}-2,-1.7 \mathrm{E}-4,-2.8 \mathrm{E}-6,-1.2 \mathrm{E}-7,2.6 \mathrm{E}-9$} \\
\hline$\omega_{\mathrm{m}}$ & $\frac{0.07 \varphi}{\left(1+7.40 \varphi-6.61 \varphi^{2}\right)}$ & $\frac{10.42 \varphi}{\left(1+5225.05 \varphi-4338.00 \varphi^{2}\right)}$ & $\frac{0.33 \varphi}{\left(1+12.53 \varphi-9.12 \varphi^{2}\right)}$ & $\frac{0.04 \varphi}{\left(1-1.85 \varphi+0.99 \varphi^{2}\right)}$ \\
\hline \multirow{2}{*}{$\delta(\mathrm{s})$} & \multicolumn{4}{|c|}{$26.1 \times 10^{-6} M_{\mathrm{w}} \cdot\left(1-\omega_{\mathrm{v}} / \omega_{\mathrm{v}, \text { sat }}\right) /\left\{R T \cdot A \cdot(10-B)\left[\left(1-\omega_{\mathrm{v}} / \omega_{\mathrm{v}, \text { sat }}\right)^{2}+B\right]\right\}$} \\
\hline & $A=5.60, B=0.20$ & $A=9.60, B=0.50$ & $A=3.00, B=0.50$ & $A=200.00, B=0.50$ \\
\hline
\end{tabular}

\footnotetext{
*Corresponding author. 13588841394(+86), 490279356@qq.com,11812013@zju.edu.cn.
} 


\section{Methodology}

A HAMT model is established by commercial software, COMSOL Multiphysics (see Figure 1). The HAMT model was validated by comparing with the benchmark cases of the HAMSTAD project ${ }^{[4]}$. According to mass and energy conservation, the governing equations of HAMT are obtained. The temperature and relative humidity at the interior surface are set according to ANSI/ASHRAE Standard $160-2016^{[5]}$. Note that the relative humidity is set at $80 \%$, the average value according to the indoor environment monitoring system, during May to model the influence caused by the particular weather (i.e., the plum rain season) in the HSCW area. The temperature and relative humidity for the exterior surface was set according to climate data of the typical meteorological year (i.e., 2005). The convective heat transfer coefficients are set at 8.7 and $23.0 \mathrm{~W} \cdot \mathrm{m}^{-2 .}{ }^{\circ} \mathrm{C}^{-1}$, respectively, at the interior and the exterior surface. The moisture transfer coefficients are obtained according to the Lewis analogy. The hygrothermal properties of materials (see Table 1) are quoted from the literature $[4,6]$. The absorptivity is set at 0.7 .

\section{Results}

Figure 2(a), (b) and (c) show the average moisture distribution in a WFTB and its surrounding area in three typical continuous days during winter, plum rain season, and summer (i.e., 30 Jan.-1 Feb., 10 May-12 May, and 10 Aug.-13 Aug.), respectively. For comparison purposes, the upper part in Figure (2) were drawn with the same legend (the right one, i.e., $4-20 \times 10^{-3}$ ), and the lower part (in the red box with dotted line) with suitable legends (the left one). It can be found in Figure 2(a) that the area with high humidity appeared at the interface between WFTB and the main part of the wall. However, at the interior surface, the area of WFTB had a relatively lower moisture content than the surrounding areas. Figure 2(b) and (c) show that the moisture content at the interior surface was quite uniform during plum rain season and summer. However, the moisture content behind the insulation material was low in plum rain season because the transfer path (outside to inside) was blocked by the insulation material.

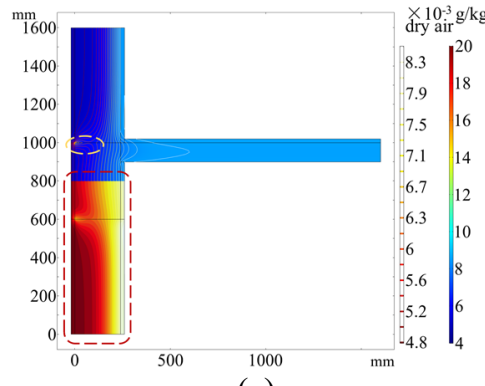

(a)

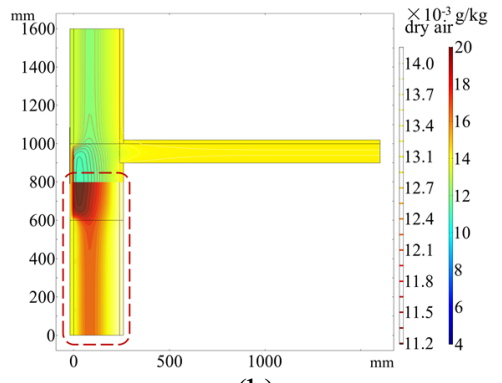

(b)

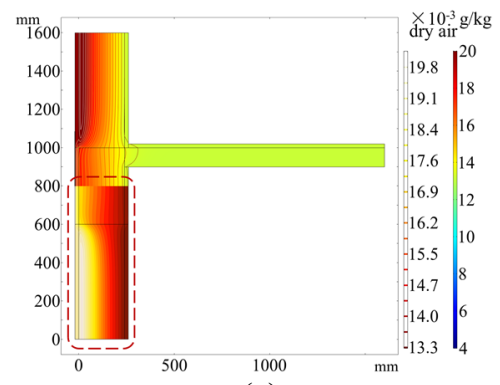

(c)

Figure 2. Average moisture distribution of air in typical days during (a) winter; (b) plum rain season, and (c) summer.

\section{Discussion and Conclusion}

Simulated results show that moisture gathers at the interface between WFTB and the main part of walls, which leads to (1) the heat losses from the interface may have a sharp rise due to the increase of thermal conductivity and the bimodal phenomenon of temperature ${ }^{[2,3]}$, and (2) the vapour in the circled area (see Figure 2(a)) has a high risk of condensation when the ambient temperature has a sudden drop. It is also found that the moisture content at the interior surface of WFTB is relatively less than the surrounding area during every season. However, as the WFTB has high thermal conductivity, the temperature of the interior surface of WFTB is lower than the others during winter, which may cause a high-relative humidity environment for mould growth. Quantifying the likelihood of mould grow and condensation is important when evaluating structure safety and indoor environment, which is worthy of future work.

In this study, the moisture distribution in the WFTB was revealed by using the analysis of HAMT. The area with a high risk of condensation was then found out. To determine whether the interior surface of WFTB is more/less suitable for mould growth, the temperature and relative humidity distribution in such area should be given attention in future research.

\section{References}

[1] Liu X., Chen Y., Ge H., Fazio P., Chen G. (2015). Numerical investigation for thermal performance of exterior walls of residential buildings with moisture transfer in hot summer and cold winter zone of China. Energy and Buildings, 93(2015) 259-268.

[2] Lu J., Xue Y., Wang Z., Fan Y., (2020). Optimized mitigation of heat loss by avoiding wall-to-floor thermal bridges in reinforced concrete buildings. Journal of Building Engineering, 30 (2020) 101214.

[3] Ge J., Xue Y., Fan Y., (2020). Methods for evaluating and improving thermal performance of wall-to-floor thermal bridges.Energy and Buildings, 110565.

[4] Department of Building Physics, Chalmers University of Technology, (2002). HAMSTAD-Final Report: Methodology of HAM-Modeling, Report R-02:8. Gothenburg.

[5] American National Standards Institute \& American Society of Heating, Refrigerating and Air-Conditioning Engineers, Inc. (2016). ANSI/ASHRAE Standard 160-2016: Criteria for Moisture-Control Design Analysis in Buildings. Atlanta.

[6] Huang J., Lv H., Feng W., (2016). Research on coupled heat and moisture transfer theory and application of homogeneous material building wall under multiple working conditions. Xuzhou. (in Chinese) 